\title{
Valve bladder syndrome in children: 0 n the trail of the best strategies to prevent chronic kidney disease
}

\author{
Dorota Polak-Jonkisz ${ }^{1, A, B, D-F}$, Leopold R. Rehan ${ }^{2, B, D}$, Konstancja Fornalczyk ${ }^{1}, \mathrm{~A}, \mathrm{~B}$, Paweł Hackemer, B, D, Danuta Zwolińska ${ }^{1, A, E, F}$ \\ ${ }^{1}$ Department of Pediatric Nephrology, Wroclaw Medical University, Poland \\ 2 Department of Internal Medicine, Occupational Diseases and Hypertension, Medical University Hospital, Wrocław, Poland \\ ${ }^{3}$ Department of Urolody, Medical University Hospital, Wrocław, Poland \\ A - research concept and design; B - collection and/or assembly of data; C - data analysis and interpretation; \\ $D$ - writing the article; $E$ - critical revision of the article; $F$ - final approval of the article
}

Address for correspondence

Leopold R. Rehan

E-mail:leopoldrehan@me.com

Funding sources

None declared

Conflict of interest

None declared

Received on November 21, 2015

Reviewed on September 14, 2016

Accepted on 0ctober 12, 2016

\begin{abstract}
Pediatric patients suffering from valve bladder syndrome (VBS) are at risk of developing chronic kidney disease (CKD) and renal failure in later life. Therefore, it is of vital importance to determine the risk factors and the best possible strategies for diagnosis and treatment in patients with VBS that would minimize the risk of developing CKD. In this review we have presented the current knowledge of CKD risk factors in patients with posterior urethal value (PUV). We have also discussed possible recommendations for prenatal diagnostics procedures to be undertaken in patients with PUV, postnatal monitoring and therapeutic strategies that could reduce the risk of developing CKD in this population. Although in most cases there are no clear guidelines for appropriate clinical actions that can be undertaken in patients with PUV to minimize the risk of kidney failure, we have tried to present concise and accurate advice for physicians taking care of patients with PUV.
\end{abstract}

Key words: chronic kidney disease, valve bladder syndrome, bladder dysfunction, posterior urethral valve

DOI

$10.17219 /$ acem $/ 65782$

Copyright

Copyright by Author(s)

This is an article distributed under the terms of the

Creative Commons Attribution Non-Commercial License

(http://creativecommons.org/licenses/by-nc-nd/4.0/) 


\section{Introduction}

In children, congenital obstructive uropathies are the cause of $30-60 \%$ of chronic kidney disease (CKD) cases. Among these, posterior urethral valve (PUV) in boys is the most prevalent. Obstructions in the urinary tract lead to its functional and anatomical changes, and then to the development of CKD., ${ }^{1,2}$

Fetal development of the urinary tract is a very complex process, involving a number of genes. ${ }^{3}$ The process of nephrogenesis begins between the $3^{\text {rd }}$ and the $4^{\text {th }}$ week of gestation, and according to Hennus et al., the onset of histological changes that lead to PUV formation can be observed already in the $4^{\text {th }}$ week of the fetal life. ${ }^{4}$ Around 95\% cases of PUVs result from abnormal insertion of the mesonephric ducts into the cloaca, followed by formation of anomalous ridges or folds. ${ }^{5}$ PUV increases the residual urine volume after bladder voiding. In 1919, Young distinguished 3 types of PUV: type I (folds which originate from the distal edge of the colliculus) - most often observed, type II (folds, originating from the proximal edge of the colliculus), and type III - with the worst prognosis (a membrane with a central hole, not linked with the colliculus). ${ }^{6}$ Modern therapeutic procedure involve endoscopic valve ablation (through urethra) shortly after the birth, but in some cases, especially in prenatal babies with too small urethras, temporary vesicostomy may be necessary. ${ }^{7,8}$ Even early surgical intervention is usually insufficient, and patients with PUV develop valve bladder syndrome (VBS); in 25-45\% CKD will develop eventually. ${ }^{7}$ Obstruction of the urine flow resulting from PUV leads to various, sometimes life-threatening consequences (Fig. 1).

Fig. 1. Consequences of the obstruction of the urine flow

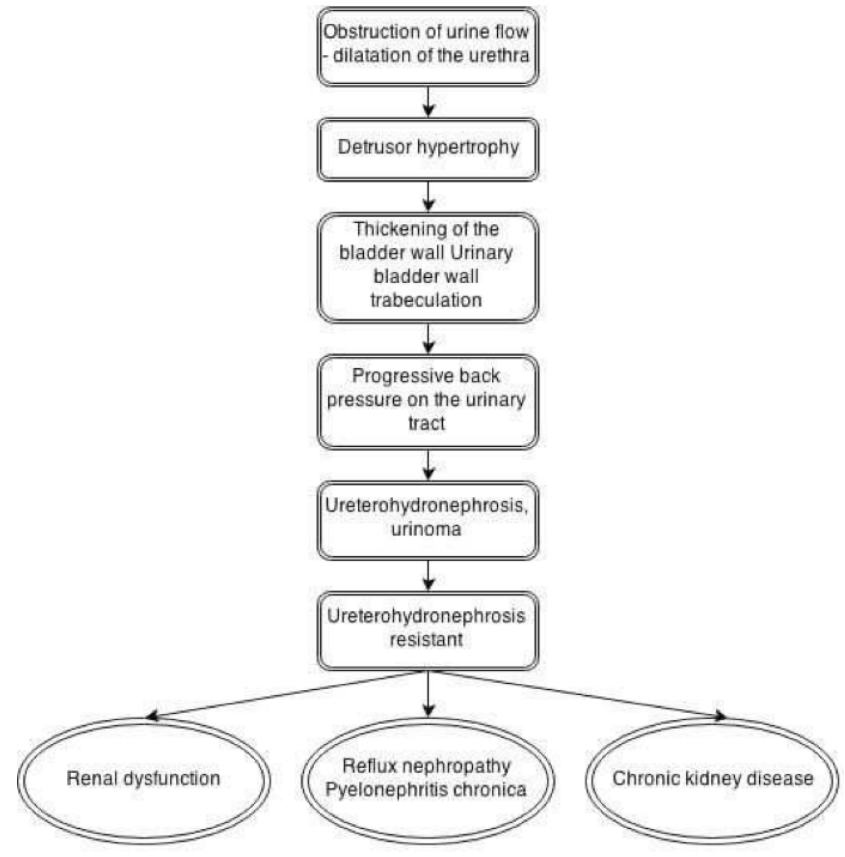

Valve bladder syndrome (VBS) was described by Mitchell (1982) as a complication of PUV, resulting in a combination of persistent upper urinary tract dilatation, hypertrophy of the bladder walls, vesicoureteral reflux, and hydronephrosis. All these changes may lead to various kidney injuries and compromise urinary bladder functions. ${ }^{1}$ Patients with VBS demonstrate considerably reduced contractility of detrusors, increased bladder compliance and a higher post-voiding residual (PVR). These parameters are described as the risk factors of dilatation of the upper urinary tract. Phases of valve bladder development can be described as follows: initially, in infants, the bladder is growing in mass, has small capacity and increased contractility. It is usually almost empty, and the voiding pressure is high. ${ }^{9}$ In the next 3 years from valve ablation, in compensated stage, volume of the bladder increases, and the pressures are maintained above the control level, because of abnormality in smooth muscles, contractility gradually decreases leading to a bladder instability. ${ }^{9}$ In the last phase, decompensation of bladder functioning is clinically apparent; the bladder capacity progressively increases, but bladder compliance, contractility and emptying are decreased (so called myogenic bladder insufficiency). ${ }^{10}$

Another serious complication of PUV exerting adverse effects on fetal development is oligohydramnios, which can cause the death of the fetus.

In almost two-thirds of the children with PUV, CKD will develop, and $11-51 \%$ of this population will progress to ESRD around the age of puberty. ${ }^{11}$

Optimal diagnostic and therapeutic procedures that will reduce the complications of PUV are of vital importance. For example, Bhadoo D. et al. proposed the "step ladder" of PUV treatment:

- valve ablation/vesicostomy,

- USPCN: Ultrasound guided percutaneous nephrostomy,

- ureterostomy.

In the analyzed cases, the primary endoscopic valve ablation was the most common initial procedure. Chronic renal failure was seen in $42.7 \%$ of the patients. In their study, the high prognostic significance of initial serum creatinine, PRA levels and GFR for developing CKD in patients with PUV was confirmed. ${ }^{12}$

\section{CKD risk factors}

Many prognostic factors for future renal function in patients with PUV have been proposed., ${ }^{1,2} 8$ A systematic monitoring of these indicators is necessary for the appropriate selection of treatment methods and the time of their implementation, optimal for delaying the onset of CKD or slowing its progression. Most important of those prognostic factors include: the age at the time of diagnosis, the serum creatinine level, considerable 
Table 1. The risk factors of developing chronic renal disease (patients before and after PUV ablation)

\begin{tabular}{|c|c|c|c|c|c|}
\hline Laboratory findings & $\begin{array}{l}\text { Kidney ultrasound } \\
\text { image }\end{array}$ & Patient's history & $\begin{array}{c}\text { Co-existing anomalies } \\
\text { of urinary tract }\end{array}$ & Surgical procedures & Urodynamic tests \\
\hline $\begin{array}{c}\text { nadir serum creatinine } \\
\quad \geq 1.0 \mathrm{mg} / \mathrm{dL}\end{array}$ & $\begin{array}{l}\text { kidney dysplasia (small } \\
\text { renal volume } \\
\text { (<3 percentile) }\end{array}$ & $\begin{array}{l}\text { age at presentation } \\
\text { before } 1 \text { year }\end{array}$ & $\begin{array}{l}\text { bilateral vesicoureteral } \\
\text { reflux, hydronephrosis }\end{array}$ & $\begin{array}{l}\text { late surgical } \\
\text { intervention }\end{array}$ & $\begin{array}{l}\text { excessive bladder } \\
\text { contraction and low } \\
\text { bladder capacity } \\
\text { in infants }\end{array}$ \\
\hline $\begin{array}{c}\text { reduced eGFR } \\
\text { at } 1 \text { year of age } \\
<90 \mathrm{~mL} / \mathrm{min} / 1.73 \mathrm{~m}^{2}\end{array}$ & kidney scarring & $\begin{array}{l}\text { urinary incontinence at } \\
\text { the age }>5 \text { years }\end{array}$ & $\begin{array}{l}\text { bladder dysfunction } \\
\text { - low susceptibility, } \\
\text { detrusor overactivity, } \\
\text { urinary retention }\end{array}$ & & $\begin{array}{c}\text { increase in bladder } \\
\text { capacity, resolution } \\
\text { of excessive } \\
\text { contraction, unstable } \\
\text { bladder function over } \\
3 \text { years from the valve } \\
\text { ablation }\end{array}$ \\
\hline $\begin{array}{c}\text { creatinine } \\
>1.0 \mathrm{mg} / \mathrm{dL} \\
\text { at } \\
\text { diagnosis of posterior } \\
\text { urethral valves }\end{array}$ & $\begin{array}{l}\text { small RPA (renal } \\
\text { parenchymal area) - } \\
\text { RPA's growth of } \\
1 \mathrm{~cm}^{2} \text { correlated with } \\
\text { a decrease in the risk } \\
\text { of ESRD), the cut-off } \\
\text { point in the study } \\
\text { assumed at the size } \\
\text { of } 12.4 \mathrm{~cm}^{2} \text { (boys with } \\
\text { RPA }<12.4 \mathrm{~cm}^{2} \text { showed } \\
\text { progression to ESRD } \\
10 \text { times more likely } \\
\text { than those with } \\
\text { RPA } \geq 12.4 \mathrm{~cm}^{2} \text { ) }\end{array}$ & growth impairment & & & $\begin{array}{l}\text { progression with age } \\
\text { to a large myogenic } \\
\text { insufficient bladder }\end{array}$ \\
\hline $\begin{array}{l}\text { high concentration } \\
\text { of urea nitrogen } \\
\text { in blood serum }\end{array}$ & increased echogenicity & $\begin{array}{l}\text { over } 3 \text { episodes } \\
\text { of febrile UTI }\end{array}$ & & & \\
\hline proteinuria & $\begin{array}{l}\text { abnormal distribution } \\
\text { of core / kidney cortex } \\
\text { ratio }\end{array}$ & hypertension & & & \\
\hline metabolic acidosis & & & & & \\
\hline
\end{tabular}

vesicoureteral reflux, renal dysplasia, and the presence or lack of the bladder dysfunction (Table 1).

A separate problem concerns renal prognosis for patients diagnosed in utero with PUV. Some authors suggest the important role of fetal urine analysis. According to Lipitz et al., sodium, calcium, and beta 2 -microglobulin in fetal urine were the best predictors for fetal survival. ${ }^{13}$ Muller et al. have assessed that the prediction of postnatal renal function can be based on the fetal urinary concentration of beta 2-microglobulin as it was both specific and sensitive test, whereas other parameters lacked either specificity (sodium, chloride, and urea levels) or sensitivity (fetal urinary glucose, phosphorus, calcium, ammonium, and total proteins). ${ }^{14}$ Another investigated parameter is fetal serum beta 2-microglobulin, whose concentration might be independent from gestational age. ${ }^{15}$ Nevertheless, there is still no consensus over the value of fetal urine assessment in CKD prognosis. For example, Morris et al. in their systematic review defined calcium and sodium levels as the most accurate predictors, and at the same time stated that current research is insufficient to determine the optimal, biochemical prognostic markers of postnatal renal function in PUV patients. ${ }^{16}$

\section{Age at the time of diagnosis}

The diagnosis of PUV at an early age is associated with a poor prognosis of further renal function and high incidence of CKD development. It is possible that this association is due to the fact that early diagnosis is often a result of more severe anatomical anomalies. ${ }^{7,9,17,18}$

\section{Nadir serum creatinine concentration}

It is accepted that the nadir serum creatinine concentration equal to or higher than $1 \mathrm{mg} / \mathrm{dL}$ in the $1^{\text {st }}$ year of life demonstrates a strong association with a higher probability of developing CKD and worse prognosis of its progression to ESRD. ${ }^{7,9,17-19}$ Some researchers postulate the importance of high serum creatinine concentration on the diagnosis of PUV as a negative prognostic factor of developing CKD or nadir serum creatinine concentration after valve ablation. ${ }^{20,21}$

\section{Glomerular filtration rate}

Also, the decline in eGFR in the $1^{\text {st }}$ year of life is widely reported as a negative prognostic factor of developing 
CKD. ${ }^{22,23}$ In 2003, Osama demonstrated that when the clearance of creatinine was lower than $60 \mathrm{~mL} / \mathrm{min} / 1.73 \mathrm{~m}^{2}$, the prognosis for renal failure in the future would be at approximately $50 \%$, while for creatinine clearance above $90 \mathrm{~mL} / \mathrm{min} / 1.73 \mathrm{~m}^{2}$, the incidence of renal failure would decrease to $27 \% .^{17}$

Some other factors are also considered in assessing the risk of developing CKD in the future or its progression to ESRD. The most often mentioned amongst them are: the existence of renal dysplasia, vesicoureteral reflux, various bladder dysfunctions (reduced contractility of detrusors, decreased bladder compliance, etc.), proteinuria and hypertension, more than 3 episodes of urinary tract infections (UTI) and late surgical intervention. , $^{1,9,17-20}$

\section{Prenatal diagnostic strategies}

Choosing an appropriate diagnostic path is of extreme importance in patients with PUV. Early diagnosis is necessary for implementing therapeutic procedures that will minimize CKD development in those patients, and reduce the rate of progression to ESRD.

\section{Ultrasound}

Ultrasound (US) imaging is used to visualize anatomical anomalies of fetal bladder in the $1^{\text {st }}$ trimester of pregnancy and dilatation in the urinary tract from $18^{\text {th }}-20^{\text {th }}$ week of gestation. Such findings usually provide an insight into potential pathologies within the urinary tract, and can also be a marker of karyotype abnormalities. ${ }^{24}$

PUV patients present a certain set of characteristic ultrasound features, mainly a dilatation of the posterior urethra, thickening of the urinary bladder wall (so-called "keyhole" sign) and dilatation within the upper urinary tract. When those features coexist with renal parenchyma pathology, oligohydramnios and pulmonary hypoplasia, identified before the $24^{\text {th }}$ week of pregnancy, they may constitute the reason for in utero surgical therapy. Unfortunately, US imaging is still an imperfect method, with significant limitations. For example, in the prenatal cases suspected of PUV analyzed by Hutton, the anomaly was confirmed after birth in only $42 \%$ of the newborns. ${ }^{10}$ The keyhole sign in US imaging is not predictive of classic posterior urethral valves and the diagnosis of "PUV" is sometimes made without positively identifying valve tissue. Type I PUV cannot be differentiated from other forms of obstruction (such as urethral diaphragm, atresia, etc.) by traditional ultrasonography. ${ }^{18,25}$ Some ultrasound specialists recognize that the resolution of today's ultrasonography is insufficient to provide a more precise anatomical diagnosis. Following a series of observations in 2009, Bernardes LS et al. found that the classical prenatal ultrasound, used to diagnose PUV, showed high sensitivity but low specificity. ${ }^{25}$ Currently, the best diagnostic indicators of PUV in prenatal US imaging are: the increased thickness of the bladder wall and the dilatation of the bladder. Another US measurement is longitudinal bladder dimension (associated with a poor renal prognosis when it exceeds $15 \mathrm{~mm}){ }^{11,26}$

\section{Assessment of fetal renal function}

Fetal urine analysis is being currently investigated as an excellent diagnostic tool for predicting the future renal function in patients with PUV. One of the laboratory values used as a predictor is the urinary sodium concentration, which helps to determine the function of renal tubules. The normal value for fetal urinary sodium concentration is below $90 \mathrm{mmol} / \mathrm{L}$ between the $20^{\text {th }}$ and the $30^{\text {th }}$ week of gestation. Sodium levels in urine above $100 \mathrm{mmol} / \mathrm{L}$ have been found to indicate a condition threatening fetal life (usually either renal or pulmonary failure). ${ }^{13,27}$

Beta 2-microglobulin is freely filtered by the normal fetal glomeruli and nearly in $100 \%$ reabsorbed in the proximal tubules, thus it can be useful as an indicator of fetal glomerular filtration rate (GFR). It also has a predictive value as to postnatal GFR. Beta 2-microglobulin detected in the urine suggests an impairment in renal tubules function. ${ }^{13,20,27}$ Other prognostic factors in fetal urine analysis, such as its specific gravity, osmolality, and the excreted volume have been defined by Glick et al. ${ }^{28}$

Tests assessing the beta 2-microglobulin in fetal urine and N-acetyl-beta-D-glucosaminidase (NAG) concentration in serum have been recently used to evaluate the degree of damage of renal parenchyma (their concentration is proportional to the extent of damage). The concentration of beta 2-microglobulin above $4 \mathrm{mg} / \mathrm{L}$ and cystatin $\mathrm{C}$ levels above $1 \mathrm{mg} / \mathrm{L}$, and the NAG levels above $6 \mathrm{mg} / \mathrm{dL}$ are thought to be poor prognostic factors for postnatal renal function. ${ }^{13,20,27,29,30}$

\section{Postnatal monitoring}

\section{Voiding cystourethrography}

In male newborns with prenatally diagnosed hydronephrosis and a "keyhole" image in US examination, associated with a high PUV probability, a prompt, extended diagnostics of the urinary system is recommended. Cystography has been established as a diagnostic "golden standard" (Fig. 2). For example, performing voiding cystourethrography (VCUG) in these cases (prenatally diagnosed hydronephrosis with high probability of vesicoureteral reflux or lower urinary tract pathologies) has been recommended by the Society for Fetal Urology and Canadian Urological association. ${ }^{31}$ VCUG can be performed without anesthesia. It reveals residual urine and vesicoureteral reflux, and is also useful in the assessment of detrusor and bladder neck activity.,32 
Fig. 2. Golden diagnostic standard for patients with prenatal suspicion of PUV

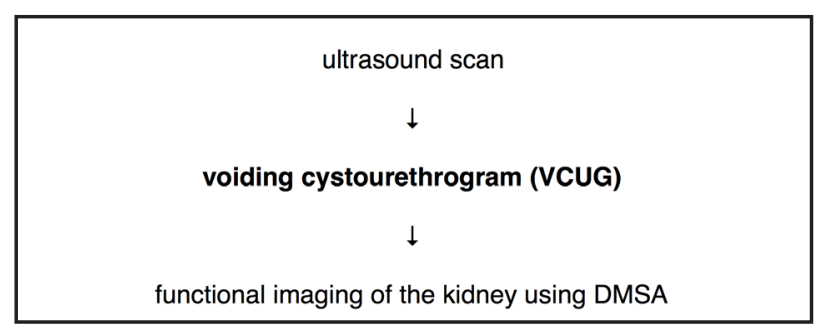

\section{Urodynamic studies}

Pathophysiological changes leading to urinary bladder dysfunction and deterioration in upper urinary tract functions in patients with PUV seem to occur even despite an early diagnosis and valve ablation.

Urodynamic tests in children are employed as an effective way to establish the urodynamic pattern of the bladder, and implement appropriate treatment. In their study involving patients with PUV, Capitanucci et al. compared the usefulness of noninvasive urodynamic evaluation vs invasive urodynamics in detecting lower urinary tract dysfunction and preventing CKD development. They have found similar effectiveness and safety of both approaches. Some patients experience strong discomfort during invasive urodynamic studies, and many decline further procedures. This gives the noninvasive approach an advantage. There are no clear guidelines regarding the frequency of performing urodynamic studies. However, it seems to be reasonable to perform them with each change in employed therapeutic method. ${ }^{33}$

\section{Late diagnosis of PUV}

Most of the children with PUV are diagnosed before birth, during a prenatal ultrasound. Sometimes, however, there are no symptoms at this stage, so the disease can go undiagnosed into childhood. Zornoza et al. described 8 cases of late diagnosed PUV in children between 1 and 14 years of age. Five patients had symptoms related to voiding dysfunction, and the other 3 were diagnosed incidentally during cystoscopy performed for another reason. All patients were operated, and after a 20-month follow-up no stenosis were diagnosed. Voiding cystourethrogram (VCUG) is a much more specific method for diagnosing PUV than an ultrasound. Diagnosis can also be made by cystoscopy, where a small camera is inserted into the urethra for direct visualization of the posteriorly positioned valve, and this method is recommended by Zornoza et al. in any case of urinary retention. ${ }^{34}$

An urodynamic investigation of valve bladder syndrome is very important. Wen et al. reported in an urodynamic study, performed in 2 groups of patients (less than 1 year and more than 1 year after urethral valve fulgura- tion), that PVR and maximum bladder capacity (MBC) increase with age after the procedure. Multiple bladder dysfunctions can be diagnosed accurately using urodynamics. ${ }^{19}$

\section{Management strategies}

An early diagnosis of PUV with its complications, including VBS, and the application of the right treatment at the right time is of key importance for the prognosis, and may prevent or delay CKD in the future.

Unfortunately, even after successful valve ablation some degree of bladder dysfunction will develop in most of the patients. This is true even for PUV patients who have been surgically treated at a very early stage of the disease. ${ }^{7,19}$ Therefore, patients with PUV require constant monitoring, also after surgical procedure, in order to detect symptoms of VBS early enough to undertake possible preventive methods.

Multi-center observations estimate the incidence of CKD in the population of boys with PUV at 10-30.4\% (in the age group from the $1^{\text {st }}$ month of life up to 18 years). ${ }^{18,35}$ Early diagnosis due to prenatal examinations (diagnostics imaging, laboratory assays, etc.) together with timely surgical interventions in utero have led to a significant decrease of mortality, and improved overall health in this group of patients. ${ }^{20,29}$ Nevertheless, we still lack the clear guidelines for the best type of surgical procedure, and each case needs individual assessment of possible risks and gains.

Strategies of limiting the risk of developing CKD in patients with VBS include diagnostic imaging, laboratory tests and therapeutic procedures. The latter are not only surgical interventions (including in utero), but also pharmacotherapy and other procedures, which mainly aim at reducing the residual urine in the bladder.

\section{Treatment possibilities}

Modern surgical techniques allow for PUV ablation performed in utero. In that case the procedure carries a significant risk of complications, such as fetal injury or even fetal or maternal death. For example, Sananes N. et al. reported 2-year outcomes after therapeutic fetal cystoscopy with ablation of PUV, where only $57 \%$ of infants survived. ${ }^{36}$ This is why intrauterine surgeries are reserved for exceptional cases (Fig. 4, 5). There is still a lack of consensus as to the advantages of intrauterine intervention over surgery after birth. ${ }^{29}$ Intrauterine treatment currently is limited to cases of fetuses with oligohydramnios and diagnosed before the $2^{\text {nd }}$ trimester. ${ }^{10,19}$ There are 3 possible treatments: amnio-bladder valve, vesicostomy and fetal endoscopic valve ablation, and none of them has definite advantage supported by evidence. ${ }^{8}$ 
A proper understanding of the molecular pathways, which are activated in damaged cells of the bladder wall, allows for appropriate pharmacological intervention in order to improve its function. ${ }^{4,22}$ Modern pharmacotherapy in VBS uses drugs like:

- cholinolytics (e.g., oxybutynin - $0.2 \mathrm{mg} / \mathrm{kg} / 24 \mathrm{~h}$ ), which decrease hyper-contractility of the bladder; therapy should be started right after valve ablation, even when urine incontinence is not presented; their use in the long term leads to a myogenic bladder failure - then it is recommended to use the CIC (clean, intermittent catheterization), but sometimes, after discontinuation of cholinolytic, the bladder function normalizes on its own; $9,18,19,37,38$

- alpha-blockers (e.g., terazosin - 0.25-2 mg), which help in bladder voiding; their use is particularly advisable when obstruction in bladder neck is suspected cause of ineffective voiding. ${ }^{10}$

Other drugs that are being tested in patients with VBS are aimed at reversing histological changes in the bladder (mainly ACEI and various growth factors inhibitors). ${ }^{39}$

Non-pharmacological procedures used in VBS management include:

- timed bladder voiding, double or even triple bladder voiding; ${ }^{10,18,38,39}$

Fig. 3. Management of urine incontinence in VBS

\begin{tabular}{c} 
pharmacotherapy \\
(cholinolytics and alpha-blockers) \\
$\downarrow$ \\
double/triple bladder voiding \\
$\downarrow$ \\
CIC \\
$\downarrow$ \\
surgery \\
\hline
\end{tabular}

Fig. 4. Steps to take before choosing the intrauterine intervention

- determination of fetal karyotype (fetuses with
obstructive uropathy are frequently diagnosed
with chromosome abnormalities)
- a close ultrasound examination in order to
detect other co-existing defects, including
heart defects
- ultrasound evaluation of fetal urinary tract
blockage (dilatation) and parenchymal
architecture of the kidney
- amniotic fluid volume assessment
- doppler ultrasound of the fetal renal arteries

- clean, intermittent catheterization (CIC) that allows for effective emptying of the bladder, also preventing urinary blockage and reducing risk of recurrent urinary tract infections; $9,10,18,22,39,40$

- as recurring urinary tract infections (UTI) are one of risk factors for CKD development in VBS patients, some authors concentrated on assessing various preventative methods. The clear rules of antibiotic preventive therapy has not been established, some recommend trimethoprim 1-2 mg nightly dose until vesicoureteral reflux recedes or age of 4-5 years. ${ }^{10,37}$ Interestingly, many authors quote arguments of the positive effects of circumcision in UTI prevention in children with PUV; ${ }^{11,37}$

- some other methods for reducing urinary retention in the bladder include pelvic floor muscles exercise and Valsalva maneuver. ${ }^{10,18}$

When all of the methods mentioned above are insufficient in reducing urine retention and improving bladder voiding, surgical procedures are performed:

- bladder augmentation, traditionally enterocystoplasty, but recently more popular ureterocystoplasty, which retains histological structure of the urinary tract; ${ }^{9,10}$

- high ureter diversion (various versions: vesicostomy, percutaneous ureterostomy, pyelostomy, nephrostomy, etc.) is controversial due to the lack of strong evidence that it can prevent CKD; ${ }^{9}$

- Mitrofanoff appendicovesicostomy is one of the treatments of the valve bladder syndrome that allows patients clean intermittent catheterization and overnight drainage when catheterization is impossible. King et al. reported that this way of treatment can achieve significant improvements in decreasing hydronephrosis and urodynamic parameters of bladder dysfunction. However, it does not prevent renal deterioration and progression to CKD. ${ }^{1,10,21}$

All treatment possibilities listed above are illustrated in Fig. 3.

Performing the valve ablation alone, without urodynamic follow-up, is inappropriate. Urinary diversion is still a very popular procedure, but recent studies suggest that in most cases in which diversion is considered,

Fig. 5. Biochemical markers of good prognosis

$$
\begin{aligned}
& -\mathrm{Na}^{+}<100 \mathrm{mEq} / \mathrm{L} \\
& -\mathrm{Cl}^{-}<90 \mathrm{mEq} / \mathrm{L} \\
& -\quad \text { osmolarity }<210 \mathrm{mOsm} / \mathrm{L} \\
& -\quad \beta 2 \text {-microglobulin }<4 \mathrm{mg} / \mathrm{L} \\
& -\quad \text { total protein }<40 \mathrm{mg} / \mathrm{dL} \\
& -\mathrm{Ca}^{2+}<8 \mathrm{mg} / \mathrm{dL}
\end{aligned}
$$


those same patients can be treated with proactive urodynamics and anticholinergic therapy achieving similar results. It is still unclear if growth factor inhibitors or angiotensin converting enzyme inhibitors have a role in preventing or reversing the histological changes of the valve bladder. ${ }^{39}$

\section{Summary}

PUV is a congenital, obstructive uropathy leading to the valve bladder syndrome, which in turn results in the development of CKD. Active urodynamic monitoring of the PUV patients plays a significant role in the prevention of bladder dysfunction, CKD development and its progression to ESRD.

Early diagnosis is currently possible even before birth (thanks to ultrasound, fetal urine analysis and some biochemical tests of fetal blood). At later stages cystography and urodynamic tests are essential to monitor the PUV patients, and determine the risk of developing CKD.

The therapeutic methods for preventing or minimizing VBS vary from surgical approach (which can be implemented in utero) through some mechanical procedures (such as timed bladder voiding and $\mathrm{CIC}$ ) to pharmacological management.

Due to the fact that cytological changes in the urinary tract, observed in children with PUV, are irreversible, medical intervention ought to be carried out with due haste after the diagnosis, but prenatal procedures, carrying a high risk of complications, are still reserved for the minority of cases.

\section{References}

1. Penna FJ, Elder JS. CKD and bladder problems in children. Adv Chronic Kidney Dis. 2011;18(5):362-369. doi:10.1053/j.ackd.2011.08.001.

2. Ansari MS, Gulia A, Srivastava A, Kapoor R. Risk factors for progression to end-stage renal disease in children with posterior urethral valves. J Pediatr Urol. 2010;6(3):261-264. doi:10.1016/j.jpurol.2009.09.001.

3. Zwolińska D, Polak-Jonkisz D, Makulska I. Podłoże genetyczne wrodzonych wad nerek i układu moczowego. Postepy Hig Med Dosw (Online). 2011;65:829-837. http://www.ncbi.nlm.nih.gov/ pubmed/22173447. Accessed June 24, 2016.

4. Hennus PML, van der Heijden GJMG, Bosch JLHR, de Jong TPVM, de Kort LMO. A systematic review on renal and bladder dysfunction after endoscopic treatment of infravesical obstruction in boys. PLoS One. 2012;7(9):e44663. doi:10.1371/journal.pone.0044663.

5. Krishnan A, De Souza A, Konijeti R, Baskin LS. The anatomy and embryology of posterior urethral valves. J Urol. 2006;175(4):12141220. doi:10.1016/S0022-5347(05)00642-7.

6. Young $\mathrm{HH}$, Frontz WA, Baldwin JC. Congenital obstruction of the posterior urethra. J Urol, 3: 289-365, 1919. J Urol. 2002;167(1):265268. http://www.ncbi.nlm.nih.gov/pubmed/11743334. Accessed June 24, 2016.

7. Yohannes $\mathrm{P}$, Hanna M. Current trends in the management of posterior urethral valves in the pediatric population. Urology. 2002;60(6): 947-953. http://www.ncbi.nlm.nih.gov/pubmed/12475647. Accessed June 24, 2016.

8. Nasir AA, Ameh EA, Abdur-Rahman LO, Adeniran JO, Abraham MK. Posterior urethral valve. World J Pediatr. 2011;7(3):205-216. doi:10.1007/s12519-011-0289-1.
9. DeFoor W, Clark C, Jackson E, Reddy P, Minevich E, Sheldon C. Risk factors for end stage renal disease in children with posterior urethral valves. J Urol. 2008;180(Suppl 4):1705-1708; discussion 1708. doi:10.1016/j.juro.2008.03.090.

10. Hutton KAR. Management of posterior urethral valves. Curr Paediatr. 2004;14(7):568-575. doi:10.1016/j.cupe.2004.07.013.

11. Pohl M, Mentzel HJ, Vogt S, Walther M, Rönnefarth G, John U. Risk factors for renal insufficiency in children with urethral valves. Pediatr Nephrol. 2012;27(3):443-450. doi:10.1007/s00467-011-1999-2.

12. Bhadoo D, Bajpai M, Panda SS. Posterior urethral valve: Prognostic factors and renal outcome. J Indian Assoc Pediatr Surg. 2014;19(3):133-137. doi:10.4103/0971-9261.136459.

13. Lipitz S, Ryan G, Samuell C, et al. Fetal urine analysis for the assessment of renal function in obstructive uropathy. Am J Obstet Gynecol. 1993;168(1 Pt 1):174-179. http://www.ncbi.nlm.nih.gov/ pubmed/8420322. Accessed June 24, 2016.

14. Muller F, Dommergues M, Mandelbrot L, Aubry MC, NihoulFekete C, Dumez Y. Fetal urinary biochemistry predicts postnatal renal function in children with bilateral obstructive uropathies. Obstet Gynecol. 1993;82(5):813-820. http://www.ncbi.nlm.nih.gov/ pubmed/8414330. Accessed June 24, 2016.

15. Ciardelli V, Rizzo N, Farina A, Vitarelli M, Boni P, Bovicelli L. Prenatal evaluation of fetal renal function based on serum beta(2)-microglobulin assessment. Prenat Diagn. 2001;21(7):586-588. doi:10.1002/pd.90.

16. Morris RK, Quinlan-Jones E, Kilby MD, Khan KS. Systematic review of accuracy of fetal urine analysis to predict poor postnatal renal function in cases of congenital urinary tract obstruction. Prenat Diagn. 2007;27(10):900-911. doi:10.1002/pd.1810.

17. Sarhan OM, El-Ghoneimi AA, Helmy TE, Dawaba MS, Ghali AM, Ibrahiem E-HI. Posterior urethral valves: Multivariate analysis of factors affecting the final renal outcome. J Urol. 2011;185(Suppl 6):24912495. doi:10.1016/j.juro.2011.01.023.

18. Ansari MS, Singh P, Mandhani A, et al. Delayed presentation in posterior urethral valve: Long-term implications and outcome. Urology. 2008;71(2):230-234. doi:10.1016/j.urology.2007.09.037.

19. Wen JG, Li Y, Wang QW. Urodynamic investigation of valve bladder syndrome in children. J Pediatr Urol. 2007;3(2):118-121. doi:10.1016/j. jpurol.2006.06.008.

20. Salam MA. Posterior urethral valve: Outcome of antenatal intervention. Int J Urol. 2006;13(10):1317-1322. doi:10.1111/j.14422042.2006.01555.x.

21. King T, Coleman R, Parashar K. Mitrofanoff for valve bladder syndrome: Effect on urinary tract and renal function. J Urol. 2014;191(Suppl 5):1517-1522. doi:10.1016/j.juro.2013.09.008.

22. Scott JE. Management of congenital posterior urethral valves. $\mathrm{Br} J$ Urol. 1985;57(1):71-77. http://www.ncbi.nlm.nih.gov/pubmed/3971107. Accessed June 24, 2016.

23. Lopez Pereira P, Espinosa L, Martinez Urrutina MJ, Lobato R, Navarro $M$, Jaureguizar E. Posterior urethral valves: Prognostic factors. BJU Int. 2003;91(7):687-690. http://www.ncbi.nlm.nih.gov/ pubmed/12699486. Accessed June 24, 2016.

24. Yiee JH, Tasian GE, Copp HL. Management trends in prenatally detected hydronephrosis: National survey of pediatrician practice patterns and antibiotic use. Urology. 2011;78(4):895-901. doi:10.1016/j.urology.2011.04.027.

25. Bernardes LS, Aksnes G, Saada J, et al. Keyhole sign: How specific is it for the diagnosis of posterior urethral valves? Ultrasound Obstet Gynecol. 2009;34(4):419-423. doi:10.1002/uog.6413.

26. Dias T, Sairam S, Kumarasiri S. Ultrasound diagnosis of fetal renal abnormalities. Best Pract Res Clin Obstet Gynaecol. 2014;28(3):403415. doi:10.1016/j.bpobgyn.2014.01.009.

27. Abdennadher W, Chalouhi G, Dreux S, et al. Fetal urine biochemistry at 13-23 weeks of gestation in lower urinary tract obstruction: Criteria for in-utero treatment. Ultrasound Obstet Gynecol. 2015;46(3):306-311. doi:10.1002/uog.14734.

28. Glick PL, Harrison MR, Golbus MS, et al. Management of the fetus with congenital hydronephrosis II: Prognostic criteria and selection for treatment. J Pediatr Surg. 1985;20(4):376-387. http://www.ncbi. nlm.nih.gov/pubmed/3900327. Accessed June 24, 2016.

29. Lissauer D, Morris RK, Kilby MD. Fetal lower urinary tract obstruction. Semin Fetal Neonatal Med. 2007;12(6):464-470. doi:10.1016/j. siny.2007.06.005. 
30. Thomas DFM. Prenatally diagnosed urinary tract abnormalities: Long-term outcome. Semin Fetal Neonatal Med. 2008;13(3):189-195. doi:10.1016/j.siny.2007.10.003.

31. Davenport MT, Merguerian PA, Koyle M. Antenatally diagnosed hydronephrosis: Current postnatal management. Pediatr Surg Int. 2013;29(3):207-214. doi:10.1007/s00383-012-3258-4.

32. Cozzi DA, Morgante D, Frediani $S$, et al. Posterior urethral valves: Relationship between vesicoureteral reflux and renal function. Urology. 2011;77(5):1209-1212. doi:10.1016/j.urology.2010.08.014.

33. Capitanucci ML, Marciano A, Zaccara A, et al. Long-term bladder function followup in boys with posterior urethral valves: Comparison of noninvasive vs invasive urodynamic studies. J Urol. 2012;188(3):953-957. doi:10.1016/j.juro.2012.04.121.

34. Zornoza M, Angulo JM, Parente A, Simal S, Burgos L, Ortiz R. Late diagnosis of posterior urethral valves. Actas Urol españolas. 2015;39(10):646-650. doi:10.1016/j.acuro.2015.05.005.

35. Kousidis G, Thomas DFM, Morgan H, Haider N, Subramaniam R, Feather $\mathrm{S}$. The long-term outcome of prenatally detected posterior urethral valves: A 10 to 23-year follow-up study. BJU Int. 2008;102(8):1020-1024. doi:10.1111/j.1464-410X.2008.07745.x.

36. Sananes N, Cruz-Martinez R, Favre R, et al. Two-year outcomes after diagnostic and therapeutic fetal cystoscopy for lower urinary tract obstruction. Prenat Diagn. 2016;36(4):297-303. doi:10.1002/pd.4771.

37. Narasimhan KL, Chowdhary SK, Kaur B, Mittal BR, Bhattacharya A. Factors affecting renal scarring in posterior urethral valves. J Pediatr Urol. 2006;2(6):569-574. doi:10.1016/j.jpurol.2005.12.003.

38. Koff SA, Mutabagani KH, Jayanthi VR. The valve bladder syndrome: Pathophysiology and treatment with nocturnal bladder emptying. J Urol. 2002;167(1):291-297. http://www.ncbi.nlm.nih.gov/ pubmed/11743343. Accessed June 24, 2016

39. Glassberg Kl. The valve bladder syndrome: 20 years later. J Urol. 2001;166(4):1406-1414. http://www.ncbi.nlm.nih.gov/ pubmed/11547099. Accessed June 24, 2016.

40. Holmdahl G, Sillen U, Hellström AL, Sixt R, Sölsnes E. Does treatment with clean intermittent catheterization in boys with posterior urethral valves affect bladder and renal function? J Urol. 2003;170:1681-1685. doi:10.1097/01.ju.0000084142.71123.b5. 